\title{
Desenho Geométrico: uma reflexão sobre currículo e práticas de ensino e aprendizagem
}

\author{
Caroline Mendes da Silva* \\ Fernanda Menezes Machado**
}

\begin{abstract}
Resumo:
Este trabalho propõe uma reflexão sobre o currículo e as práticas pedagógicas relacionados ao ensino do Desenho Geométrico na educação básica por meio de uma pesquisa exploratória. Para isso, investigou-se o histórico da disciplina na educação no Brasil para que entendêssemos sua atual situação nas escolas, especificamente no Colégio de Aplicação da Universidade Federal do Rio de Janeiro. $O$ objetivo foi pesquisar algumas maneiras diferentes das abordagens tradicionais do ensino de Desenho para que, de alguma forma, os alunos tivessem mais interesse com os processos de construção gráfica propostos pelo currículo escolar. Diante de algumas práticas multidisciplinares e metodologias descritas dentro da concepção de Design Thinking, percebeu-se um maior envolvimento destes alunos no processo de desenvolvimento teórico e prático do Desenho Geométrico.
\end{abstract}

\section{Palavras-chave:}

Educação. Ensino. Desenho. Projeto.

\begin{abstract}
:
This work proposes a reflection on the curriculum and pedagogical practices related to the teaching of Geometric Design in basic education through an exploratory research. For this, the history of the discipline in education in Brazil was investigated so that we could understand its current situation in schools, specifically at the College of Application of the Federal University of Rio de Janeiro. The objective was to research some different ways from the traditional approaches to teaching Drawing so that, in some way, students were more interested in the graphic construction processes proposed by the school curriculum. Faced with some multidisciplinary practices and methodologies described within the Design Thinking concept, it was noticed a greater involvement of these students in the process of theoretical and practical development of Geometric Design.
\end{abstract}

\section{Keywords:}

Education. Teaching. Design. Project.

\footnotetext{
* Graduada em Licenciatura em Educação Artística com habilitação em Desenho pela Universidade Federal do Rio de Janeiro. Docente substituta no Colégio de Aplicação da UFRJ atuando no ensino básico e na formação de professores, nas áreas de Desenho Geométrico e Desenho Projetivo. E-mail: caroline.mendes@live.com. ORCID iD: https://orcid.org/0000-0002-0649-924X.

** Pós-graduada em Design de Moda pelo Senai Cetiqt. Graduada em Licenciatura em Educação Artística com habilitação em Desenho pela UFRJ e Desenho Industrial pela Universidade da Cidade. Docente substituta do Colégio de Aplicação da Universidade Federal do Rio de Janeiro, atuando no ensino básico e na formação de professores, nas áreas de Desenho Geométrico e Desenho Projetivo. E-mail: fefemmachado@gmail.com. ORCID iD: https://orcid.org/0000-0001-8084-9546.
} 
"Não podemos solucionar problemas usando o mesmo padrão de pensamento que utilizamos para criá-los." Albert Einstein

\section{Introdução}

Historicamente o Desenho como área de conhecimento tem origem no estudo da filosofia, da astronomia e particularmente da Geometria, pois se tinha uma grande necessidade de compreender o ser humano e tudo que há a sua volta, o mundo. A partir das experiências pessoais, ao longo da vida acadêmica e em sala de aula, como professoras, no Colégio Aplicação da UFRJ foi observado que o ensino do Desenho Geométrico no decorrer do tempo se desconectou do mundo, desprendeu-se tanto da realidade dos alunos que acabou por se tornar uma matéria sem sentido para eles, além de ser uma das matérias com um dos maiores índices de alunos em recuperação.

A disciplina do Desenho vem perdendo o prestígio, sendo negligenciado por muitas escolas, porém sua importância para o desenvolvimento do aluno é incontestável. A valorização da disciplina e a volta a sua essência pode vir com a incorporação de Design e do Design Thinking as suas práticas pedagógicas além da elaboração de projetos multidisciplinares em que os alunos possam definir a área de interesse e direcionar o seu estudo.

\section{Breve história do ensino de Desenho Geométrico no Brasil}

Inicialmente, é importante relatar como ocorreu o desenvolvimento do ensino de Desenho Geométrico no Brasil desde os seus primórdios para que possamos entender sua importância dentro dos diferentes contextos históricos da educação no país.

O ensino de Desenho no Brasil começou no final do séc. XVII por interesse de Portugal em proteger e defender a terra conquistada sendo esse ensino aplicado na formação militar (COSTA; ROSA, 2015). Desse modo, iniciaram-se as "primeiras iniciativas de um ensino de ciências, especialmente de matemática e desenho, a fim de formar pessoal capacitado para trabalhos com fortificações militares" (MACHADO, 2012, p. 53). Em 1699 foram criadas, no Rio de Janeiro, aulas de fortificação, com o objetivo de ensinar a desenhar e projetar as fortificações no país, pois umas das ameaças eminentes era a possível guerra entre Portugal e Espanha no séc XVIII, gerando a necessidade de defesa (COSTA; ROSA, 2015). Este acontecimento foi determinante para tornar obrigatório o estudo de Desenho no ensino militar para os oficiais militares.

No séc. XIX, com a transferência da família real portuguesa para o Brasil, o sistema educacional (quase inexistente) da colônia foi revisto, realizando alterações para atender melhor os interesses da Corte Portuguesa em 1811. Nesse contexto, foi criada a Academia Real Militar a fim de consolidar "o ensino sistemático das matemáticas, das ciências e da técnica do Brasil, no início do século XIX” (ZUIN, 2001, p. 64).

Após a chegada de D. João VI ao Brasil, a necessidade de se estabelecerem as profissões técnicas e científicas faz com que sejam criados cursos de Desenho no país. Para começar a reverter este quadro, em 1816, a Missão Francesa composta por 18 integrantes chega ao Rio de Janeiro, a convite de D. João VI, para organizar e criar a Escola Real de Ciências, Artes e Ofícios no Brasil. Em 1817, é criado o curso de Desenho em Vila Rica. No entanto, apenas após abolição da escravatura, as artes e os trabalhos manuais começam a ser mais valorizados. (ZUIN, 2001, p. 64).

Anteriormente, no séc. XVIII, aconteceu na Europa a Revolução Francesa e a Revolução Industrial, gerando um impacto mundial nos avanços do processo produtivo em nível econômico, tecnológico e social (COSTA; ROSA, 2015). No cenário da revolução Industrial, o Desenho Geométrico era considerado como um saber fundamental que possibilitou a modernização das máquinas industriais (MACHADO, 2012). "A partir do Ato Adicional de 1834 começaram a ser tomadas providências com o intuito de organizar esse 
ramo de ensino, sendo criadas as Escolas Normais, os Liceus Provinciais a partir de 1835, e ainda o Colégio Pedro II em 1837" (MACHADO, 2012, p. 59). Assim, a criação dessas instituições permitiu que o ensino do Desenho Geométrico se difundisse, sendo desvinculado dos ateliês particulares e das escolas militares.

Rosilene Machado (2012) explica que no início do séc. XX, pós-segunda guerra mundial, em plena crise global, o Brasil sofreu algumas restrições às importações, sendo obrigado a implementar uma indústria nacional mais efetiva. Contudo, o processo de desenvolvimento industrial nacional, por ser bem embrionário, demandava urgentemente de uma formação de mão de obra especializada favorecendo ao ensino de Desenho e da educação em geral.

No final do século XIX, Rui Barbosa, jurista e parlamentar, guiou-se na forma de educação europeia para a elaboração de um projeto de reforma do Ensino Médio, que visava um sistema nacional de ensino gratuito, obrigatório e laico. Nesse projeto, foi definido de que o Desenho Geométrico devesse ser considerado como um "saber escolar necessário para o desenvolvimento industrial brasileiro" (MACHADO, 2012, p. 63). "Pode-se inferir, inclusive, que as décadas de 1930 a 1950 constituíram os anos de ouro dessa disciplina em nosso país, dada sua visibilidade em meio aos documentos educacionais oficiais" (MACHADO, 2012, p. 68).

Após os anos de auge do Desenho Geométrico, na década de 60 se inicia o seu desprestígio, com a entrada em vigor da primeira Lei de Diretrizes e Bases da Educação Nacional — LDB 4.024/61, que transformava a disciplina em uma das optativas a serem oferecidas. Então, após a retirada do Desenho Geométrico como uma disciplina curricular obrigatória, o seu ensino foi removido do currículo da maioria das escolas brasileiras e o seu conteúdo não era mais exigido na programação dos principais vestibulares do Brasil.

Na década de 90 entra em vigor uma nova LDB - Lei 9.394/96 - que, logo depois, foi complementada pela publicação dos Parâmetros Curriculares Nacionais e pela criação de vários mecanismos de avaliação da qualidade do ensino básico, entre eles o Exame Nacional do Ensino Médio (ENEM). Os PCN mantiveram o ensino de Desenho excluído dos currículos escolares, repartindo os objetivos, habilidades e competências por ele anteriormente trabalhadas entre as Artes e a Matemática.

A partir do biênio 2014-2015, por ocasião da abertura de consultas públicas para a organização da BNCC, a possibilidade de reintegração do Desenho à matriz curricular obrigatória voltou a ser acalentada, em grande parte por iniciativa de professores do departamento de Desenho e Artes Visuais do colégio Pedro II, no Rio de Janeiro. (BUENO, 2017, p. 18).

Atualmente, o Desenho Geométrico é considerado uma disciplina optativa não obrigatória, porém algumas escolas de referência educacional ainda o mantém em sua grade curricular como uma disciplina ou dentro de outras disciplinas como Matemática ou Artes Visuais.

\section{Formação de professores de Desenho na Escola de Belas Artes da UFRJ}

O curso de licenciatura em Educação Artística com Habilitação em Desenho da Escola de Belas Artes, na Universidade Federal do Rio de Janeiro é formado, basicamente, por quatro "grupos" de disciplinas que se acomodam em diferentes departamentos dentro da Escola de Belas Artes da UFRJ. São esses: as artes com disciplinas práticas, voltadas para o Desenho Artístico e outros tipos de expressões artísticas; a história da arte, que abrange diversas disciplinas teóricas envolvendo arte, filosofia e história; a educação, com as disciplinas comuns da licenciatura na UFRJ mais as práticas e metodologias de ensino de Desenho; e as “técnicas”, que abrangem desde Desenho Geométrico Básico, Teoria do Desenho Geométrico, Geometria Descritiva até Desenho de Máquinas, de Móveis e de Arquitetura.

Esta perspectiva transformadora vai exigir mudanças didáticas nos currículos, pois estes estão sobrecarregados de conteúdos insuficientes para a vida profissional, já que a complexidade dos problemas atuais exige novas competências além do conhecimento específico, tais como: colaboração, conhecimento interdisciplinar, habilidade para inovação, trabalho em grupo, educação para o desenvolvimento sustentável, regional e globalizado. (GEMIGNANI, 2012, p. 3). 
Ao observarmos o currículo e as aulas da licenciatura em Desenho da UFRJ, vimos que as disciplinas relacionadas a Desenho têm, muitas das vezes, uma abordagem muito técnica dos processos de construção gráfica, voltado, quase sempre, apenas para o cumprimento de normas da ABNT e não constroem qualquer tipo de conexão com a realidade profissional do então futuro professor. Apenas quando chegamos à prática de ensino (estágio supervisionado obrigatório) que começamos a despertar um olhar concernente ao desenvolvimento do conhecimento e finalidade do ensino de Desenho.

Como destaca Jacques Delors (1999), em seu relatório da Comissão Internacional sobre Educação para o século XXI para UNESCO, a educação deve organizar-se à volta de quatro aprendizagens fundamentais que, ao longo de toda a vida, serão de algum modo, para cada indivíduo, os quatro pilares do conhecimento: aprender a conhecer, isto é, adquirir os instrumentos da compreensão; aprender a fazer, para poder agir sobre o meio envolvente; aprender a conviver, a fim de participar e cooperar com os outros em todas as atividades humanas e, finalmente, aprender a ser, via essencial que integra os três precedentes. (GEMIGNANI, 2012, p. 4-5).

A maioria os estudantes chegam à prática de ensino quando estão nos últimos períodos da faculdade. O que é bom, pois eles chegam com certa "bagagem de conhecimento" para lidar com o currículo escolar. Mas poderia ser ainda melhor se desde antes eles já estivessem envolvimento com projetos e atividades inclinados para o pensamento e planejamento de metodologias de ensino que gerassem engajamento dentro do processo de ensino e aprendizagem. "A Universidade deve ser o lugar onde o estudante adquira habilidades educacionais, profissionais, analíticas e de trabalho, ou seja, saiba utilizar o pensamento científico. Para tanto, a avaliação deve ter como objetivo ajudar o estudante a amadurecer e melhorar de forma constante" (GEMIGNANI, 2012, p. 5).

Até o então momento, o curso não conta com a obrigatoriedade de um trabalho final de conclusão de curso. Para além de uma experiência a mais com a prática de pesquisa, poderia ser também uma boa saída para uma continuidade de construção, não só metodológica, prática, do Desenho, mas também filosófica, de afirmação de sua importância dentro de um cenário em que ele não consta mais como obrigatório no ensino básico do país.

Além do curso de licenciatura em Desenho da UFRJ, no Brasil, também temos cursos semelhantes como os de Expressão Gráfica, da Universidade Federal do Paraná, e a licenciatura em Expressão Gráfica, da Universidade Federal de Pernambuco. São dois cursos que, pela análise do currículo, têm uma abordagem interessantíssima do Desenho e trabalhada com mais fluidez do processo de construção das ideias.

\section{As aulas de Desenho na escola}

O primeiro contato dos alunos do CAp-UFRJ com Desenho acontece quando eles chegam ao sexto ano. É quando eles conhecem todo material de Desenho (caderno de desenho, par de esquadros, compasso e transferidor) e elementos fundamentais do Desenho (conceito de ponto, reta e plano, por exemplo) que os acompanhará até o segundo ano do Ensino Médio.

Para uma boa parcela dos estudantes, Desenho é uma matéria muito difícil, que não deveria nem existir. Um questionário respondido por uma turma de trinta alunos de primeiro ano do Ensino Médio revelou que pouco mais da metade deles via o Desenho como matéria sem muita importância na escola, pois não conseguiam enxergar nela qualquer aproveitamento.

Fomos analisar os recursos didáticos disponíveis e percebemos que talvez não estejamos oferecendo os melhores estímulos. Não adianta termos ilustrações bonitas em um livro se os exemplos são forçados. Assim como não adianta ter todos os recursos tecnológicos se a abordagem, a forma de fazer, os resultados, serão os mesmos. Uma sala de aula com trinta alunos dispõe de diversos elementos mais interessantes que qualquer matéria exposta sobre a lousa. 
No CAp-UFRJ existe a classe experimental do sexto ano, cuja dinâmica pedagógica tem sido diferente desde o ano letivo de 2018. Estes estudantes foram divididos em dez grupos. Cada grupo aborda um eixo de pesquisa diferente, tendo um professor orientador por grupo. É um projeto desenvolvido por todos os professores da série e foi inspirado nos projetos Amora e Pixel do Ensino Fundamental II do CAp-UFRGS. Esses projetos trazem para o corpo discente a experiência de autonomia no processo de aprendizagem através da pesquisa.

Nesse tipo de organização, os tempos de aula não foram descartados para que a aprendizagem seja única e exclusivamente por meio de projetos interdisciplinares. A grade horária ainda existe para contemplar as disciplinas regulares. A diferença é que dentro da grade existem dois tempos por semana destinados para esse momento de desenvolvimento de projeto. Uma coisa que pode dificultar bastante esse processo é a tentativa de encaixar o currículo fechado em um projeto multidisciplinar - acaba sendo uma opção dificultadora para o desenvolvimento de trabalho. Por isso, às vezes, trabalhar por projeto mais com um currículo fechado pode acabar sobrecarregando não só os alunos, mas também o corpo docente se não houver uma reforma curricular que otimize o trabalho.

Por mais que ainda não seja possível implementar esse modelo de trabalho para toda a escola, ainda assim, é possível estudá-lo e usá-lo como inspiração para desenvolvimento de projetos, mesmo que o projeto "se restrinja" apenas ao Desenho em cada série.

\section{Tendências}

O mundo tem mudado com tanta velocidade e para direções tão diferentes que constantemente nos encontramos perdidos em meio a tantas informações e coisas novas.

Hoje, os nossos celulares, que são indispensáveis no dia a dia, têm capacidade de armazenamento e processamento maiores do que os primeiros foguetes que chegaram à Lua (DESCOLA, 2019). O estudo Ageing populations: the challenges ahead (CHRISTENSEN; DOBLHAMMER; RAU, 2018), publicado na revista científica The Lancet, afirma que a expectativa de vida de pessoas nascidas nos anos 2000 já supera os 100 anos e, de acordo com Alicia Bárcena, chefe da Comissão Econômica para a América Latina e Caribe (CEPAL), 65\% dos jovens de hoje vão trabalhar em profissões que ainda nem foram inventadas.

É evidente que essas mudanças geram impacto em nossas vidas, mas não se é pensado o quanto isso tudo muda o mercado de trabalho e a nossa forma de aprender e ensinar?

Empresas como Google, Apple, IBM ou EY não exigem mais um diploma para contratar um profissional. Elas estão muito mais preocupadas com conhecimentos e habilidades diversas e complementares dos seus colaboradores do que uma especialização. É importante que um colaborador saiba de marketing, mas que também entenda de algumas correntes de administração, de psicologia, de gestão, de negociação, de filosofia e de storytelling. O que quer dizer tudo isso? Que você não pode mais parar de aprender. Um dos termos mais usados é o Lifelong Learning ${ }^{1}$, que é relacionado ao aprendizado ao longo da vida. Num mundo em que tudo muda, vamos ter que aprender que mudanças são essas e quais são as habilidades fundamentais que precisamos desenvolver nesse novo mundo. (DESCOLA, 2019).

Mediante toda essa mudança que vivemos, é nítido que a escola não está conseguindo acompanhar o mundo na mesma velocidade.

O formato de escola que conhecemos hoje em dia foi desenvolvido e planejado na era industrial, visando atender as demandas no mercado de trabalho e as configurações das fábricas da $1^{\mathrm{a}} \mathrm{e} 2^{\mathrm{a}}$ Revolução

1. Em português, educação continuada. Este conceito, que está tão em alta no mundo corporativo, indica que a aprendizagem deve acontecer ao longo da vida toda, e não em um período determinado (escola e universidade e, às vezes, especializações e pós-graduações). A partir dessa visão, uma pessoa tem capacidade de aprender independentemente da idade e do método de ensino e em diversos contextos - não necessariamente apenas pela educação formal. (DESCOLA, 2019). 
Industrial, lá pelo século XVIII. Nas escolas, os alunos são divididos em níveis, sentam-se em filas e fileiras, usam uniformes, a sinaleta avisa a hora do intervalo e da saída, o professor é chefe da sala de aula.

Hoje, porém, estamos na era digital, onde tudo acontece muito rápido. Existe um fluxo de informação intenso que a todo momento é atualizado e rapidamente algumas informações já ficam obsoletas. O mercado de trabalho está procurando assimilar essas grandes transformações, mas a educação não está sabendo como fazer isso e mantém o mesmo sistema educacional da era industrial. Essa estagnação da educação gera um distanciamento entre a escola e o mundo real, promovendo um desinteresse dos alunos porque as aulas são chatas e os estudantes não conseguem ver o objetivo de todo aquele conteúdo.

Segundo José Pacheco, mestre em Educação da Criança pela Universidade do Porto e fundador da Escola da Ponte, em 1976, na cidade de Porto, em Portugal, defende que a escola do século XXI seja totalmente diferente dos modelos tradicionais, sem turmas ou ciclos, provas, reprovações e sem campainhas que delimitam os horários. Ao fundar a Escola da Ponte, ele coloca em prática toda a teoria de como deveria ser a escola da era digital. As tecnologias forçam o desenvolvimento de uma nova realidade educacional, não permitindo aos professores ter o monopólio do conhecimento e aplicando a uma metodologia que combine a criatividade, a automotivação e a aprendizagem prática. Pela vivência pedagógica da Escola da Ponte, podemos dizer que será fácil apropriar-se dos novos desafios da educação contemporânea, isto é, "de novas formas de relacionamento com o conhecimento, a potenciar uma comunicação global com os diferentes intervenientes na comunidade educativa" (PACHECO; SILVA, 2011, p. 8).

A Escola da Ponte é baseada em três valores principais: a liberdade, a responsabilidade e a solidariedade, e em nada se assemelha às escolas comuns. As crianças e os adolescentes que lá estudam definem quais são suas áreas de interesse e desenvolvem projetos de pesquisa, tanto em grupo como individuais.

Mencionamos a Escola da Ponte por ser a prática da teoria filosófica e científica de John Dewey e Paulo Freire, por ser um modelo de escola que deu certo ao experimentar metodologias diferentes das tradicionais.

\section{Pensando sobre o ensino de Desenho: qual seria a tendência do Desenho Geométrico?}

Em virtude de tudo que já foi citado anteriormente, o ensino do Desenho Geométrico vem sendo ensinado, desde então, de uma forma tradicional com métodos um tanto ultrapassados. De fato, o ensino precisa se adequar à nova era para fazer sentido aos alunos.

As configurações de trabalho atualmente ainda são dadas por disciplinas independentes, cada uma trabalhando seus conteúdos específicos, relacionando-os, muitas vezes, com aspectos do cotidiano, mas poucas vezes se relacionam com as demais disciplinas disponíveis no currículo escolar dos alunos. Então, a crença de que um ensino multidisciplinar, com projetos de pesquisa, onde os alunos podem definir a área de interesse, nos direciona para um ensino de Desenho Geométrico mesclado com Design e Design Thinking, pois se pode mostrar na prática como o Desenho dialoga com diferentes áreas do conhecimento como engenharia, arquitetura, moda, games, jogos, etc.

O Design Thinking é uma "abordagem" que visa a solução de problemas complexos, sempre com o foco nas pessoas, contemplando as necessidades individuais e coletivas. Na educação, é conhecido como aprendizagem investigativa, trabalhando de forma colaborativa e desenvolvendo a empatia (GAROFALO, 2018). Nesse modelo, o estudante participa como formador de conhecimento e não apenas como receptor de informação e se utiliza da criatividade e de conhecimentos multidisciplinares além de significar o próprio aprendizado.

Não existe uma única forma correta de aplicá-lo. O que existe são etapas a serem exploradas como processo de resolução de problemas. Quando usadas em sala de aula, essas etapas trazem mais dinamismo, envolvimento e sentimento de pertencimento. Ao propor novos processos de ensino e aprendizagem, o Design Thinking colabora para um redesenho das aulas. (GAROFALO, 2018). 


\section{Metodologia}

No Colégio Aplicação da UFRJ as aulas de Desenho Geométrico são lecionadas de forma técnica e tradicional, o que é intrigante por ser a mesma práxis de séculos atrás e é isso que justifica esse estudo e investigação sobre o ensino de Desenho.

O estudo usa a abordagem do Design Thinking (aprendizagem investigativa) e os as referências práticas desenvolvidas na Escola da Ponte descritas por José Pacheco e Andrea Silva citados no capítulo anterior. Essas abordagens teóricas foram aplicadas nas turmas do $6^{\circ}$ e do $9^{\circ}$ ano do Ensino Fundamental. O desenvolvimento do estudo com cada série teve um tratamento diferente, pois o $6^{\circ}$ ano do EF estava trabalhando com projetos interdisciplinares e no $9^{\circ}$ ano o conteúdo era dividido em disciplinas.

A prática metodológica foi dividida em 5 etapas: descoberta, interpretação, ideação, experimentação e evolução, descritas pelo "manual de ferramentas" online Design Thinking for Educators ${ }^{2}$, desenvolvido por professores estadunidenses da escola independente Riverdale Country School.

" A etapa da descoberta é construída com desafios e propostas que agucem a curiosidade. É nesse processo que os alunos escolhem a sua equipe de trabalho (no mínimo 2 e no máximo 4 pessoas), compartilham o que sabem sobre o assunto, definem o que precisam saber e vão em busca de saber. Observam também o perfil das pessoas que são impactadas com a proposta, fazem entrevista e pesquisa de campo.

»A etapa da interpretação significa toda a pesquisa e coleta de dados feitas, define o perfil das pessoas que são impactadas e é quando é exposto tudo o que foi aprendido.

" A etapa da ideação tem como base inspiracional a etapa anterior, pois é na ideação que acontece a geração de várias ideias. A "chuva de ideias" (o famoso brainstorming) encoraja a pensar de forma expansiva, sem amarras e julgamentos. Muitas vezes, as ideias mais ousadas são as que desencadeiam pensamentos visionários. Nessa etapa também acontece a seleção de algumas ideias que poderão se tornar a solução ideal para o problema.

» A etapa da experimentação é o momento de dar vida as ideias, com a construção de protótipos. Mesmo com protótipos iniciais e rústicos é possível obter respostas diretas e aprender como melhorar e refinar uma ideia.

" Na etapa de evolução, a ideia é refinada é verificado se esta atende a todas as necessidades listadas nas etapas anteriores. São aplicados testes de validação e pontos de melhoria são identificados para a evolução do projeto, além do planejamento dos próximos passos.

\section{Nono ano do Ensino Fundamental: projeto de identidade visual}

Proposta: desenvolvimento de uma identidade visual da turma do $9^{\circ}$ ano de 2019 para ser um símbolo do fechamento do ciclo do Ensino Médio, representando toda a trajetória acadêmica da turma, utilizando o conhecimento de transformações pontuais. Posteriormente, uma logo (representação gráfica que determina uma identidade visual, nesse caso a identidade visual da turma), seria escolhida por votação dos alunos e professores e seria estampada no copo do churrasco de encerramento do ciclo dos alunos. Parte do projeto foi desenvolvido em sala e parte pelos grupos, sem a supervisão da professora, de forma autônoma.

» Na etapa da descoberta, os alunos dividiram-se em grupos e começaram a pesquisar características da turma, destacando as que mais os identificava. Pesquisaram mais sobre as transformações pontuais, onde e como são usadas em logos e identidades visuais. Essa era uma etapa preocupante, pois a turma 19B tinha um histórico de ter alguns problemas relacionais na turma, mas eles souberam se dividir muito bem e até alunos que pareciam estar excluídos foram integrados por algum grupo sem intervenção da professora. 
Figura 1 - Etapa de descoberta

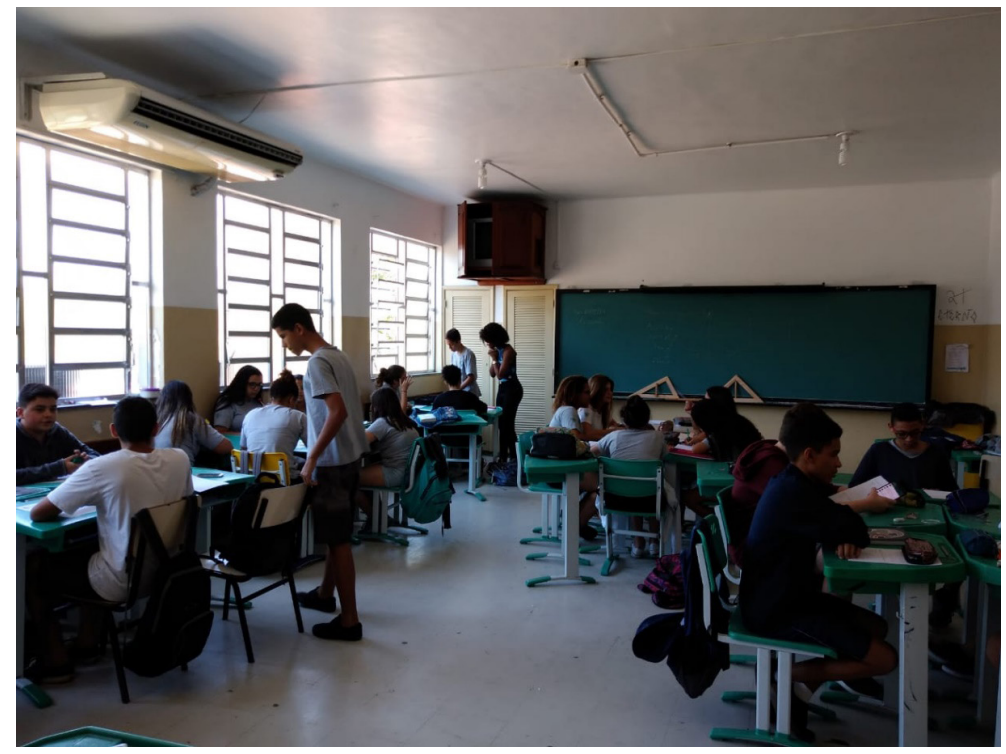

Fonte: Elaborada pelas autoras.

» Na etapa de interpretação, eles reuniram todos os itens pesquisados, definiram um perfil da turma e pensaram em símbolos, formas e cores que pudessem representar o que eles queriam comunicar (a turma se surpreendeu por se enxergarem tão diferentes e tão unidos ao mesmo tempo).

» Na etapa de ideação, os alunos fizeram uma "chuva de ideias", com esboços rústicos a mão livre de possíveis logos. Foi difícil explicar que todas as ideias deveriam ser aceitas sem julgamentos, pois só depois seriam analisadas.

» Na etapa experimentação, eles escolheram as ideias que melhor se adequaram aos objetivos do grupo e desenvolveram alternativas com alguns esboços mais elaborados, com o uso do instrumental de Desenho Geométrico. Nessa etapa, houve uma procura maior dos alunos pela professora para auxiliá-los no desenho das transformações pontuais.

Figura 2 - Etapa de experimentação

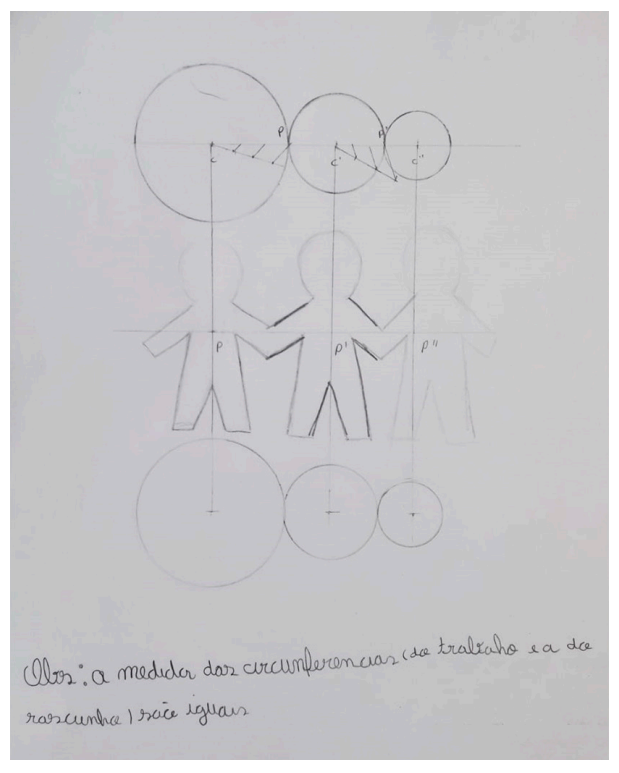

Fonte: Acervo das autoras.

A Figura 2 apresenta o processo inicial de criação. Podemos ver os traçados das construções das formas, como os centros das circunferências, os eixos de reflexão das formas e a relação proporcional de uma circunferência em relação à outra. 
" Na etapa de evolução, uma das alternativas foi escolhida e desenvolvida, chegando a uma arte final. Para defender a sua logo, cada grupo desenvolveu um vídeo que justificava a logo e que foi postada, com autorização dos alunos, na conta do Instagram ${ }^{3}$ da aula de Desenho para ser votada. Infelizmente, não tivemos verba para estampar a logo vencedora nos copos. Essa etapa foi surpreendente, em ver toda a criatividade dos alunos e dos vídeos produzidos por eles e de sentir o quanto essa proposta serviu para eles enxergarem e se unirem como turma.

\section{Figura 3 - Etapa de evolução: composição gráfica finalizada}

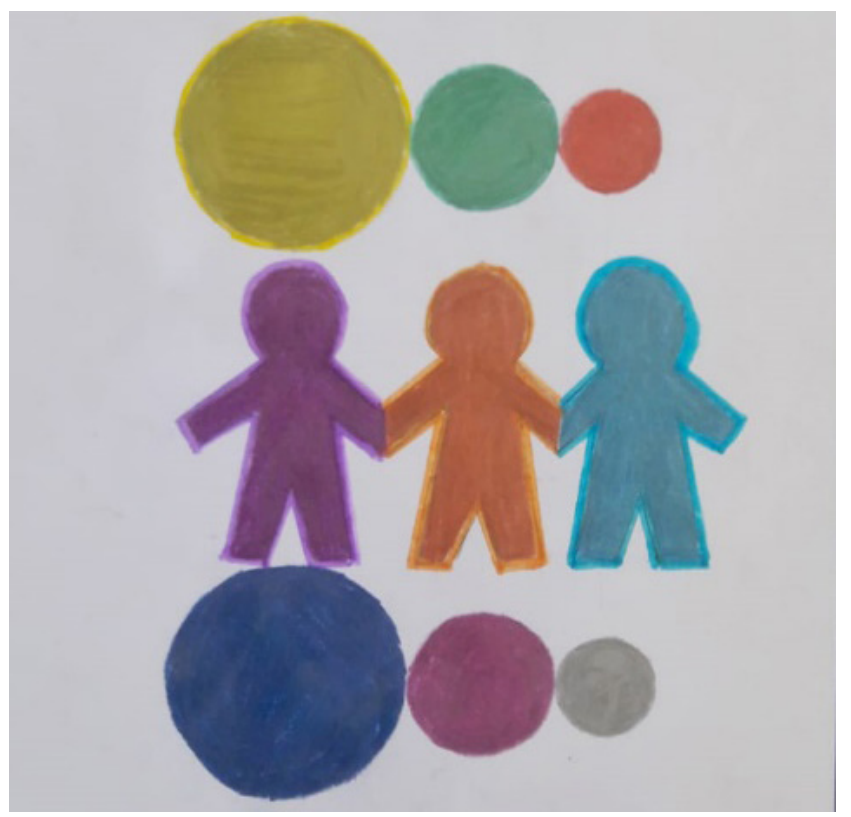

Fonte: Acervo das autoras ${ }^{4}$

Figura 4 - Etapa de evolução: composição gráfica finalizada

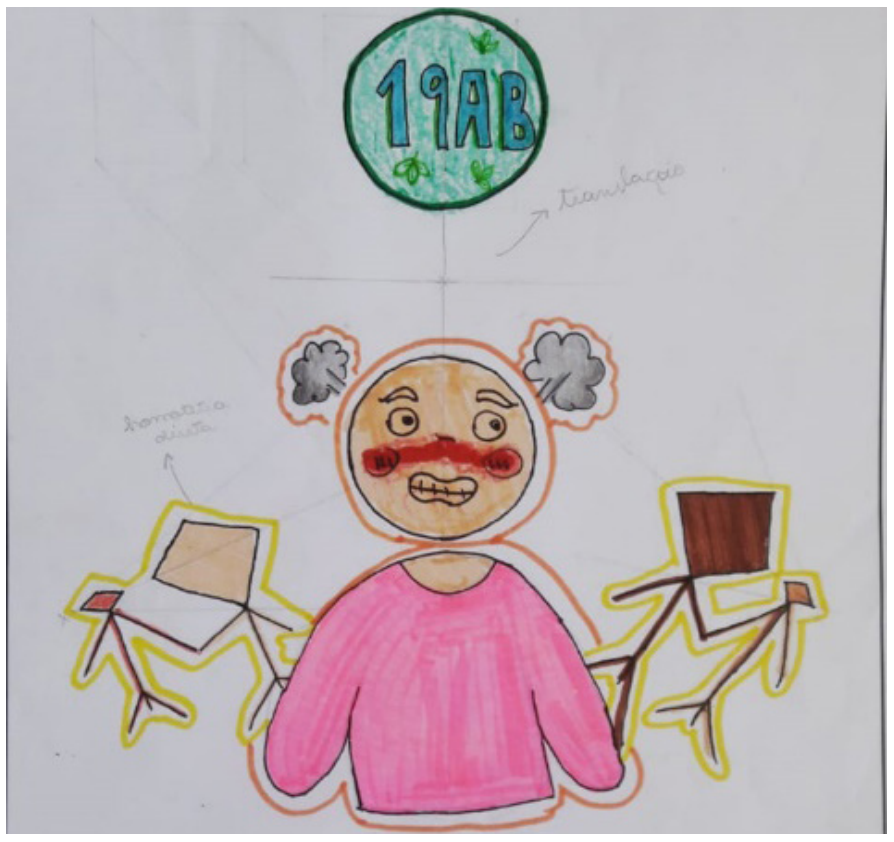

Fonte: Acervo das autoras 5 .

3. A conta pode ser acessada através do seguinte link: https://www.instagram.com/desenho_cap/?hl=pt-br.

4. Link de acesso ao vídeo: https://youtu.be/6xzY2wLfnl4.

5. Link de acesso ao vídeo: https://youtu.be/4009hEDiBKw. 
Figura 5 - Etapa de evolução: composição gráfica finalizada
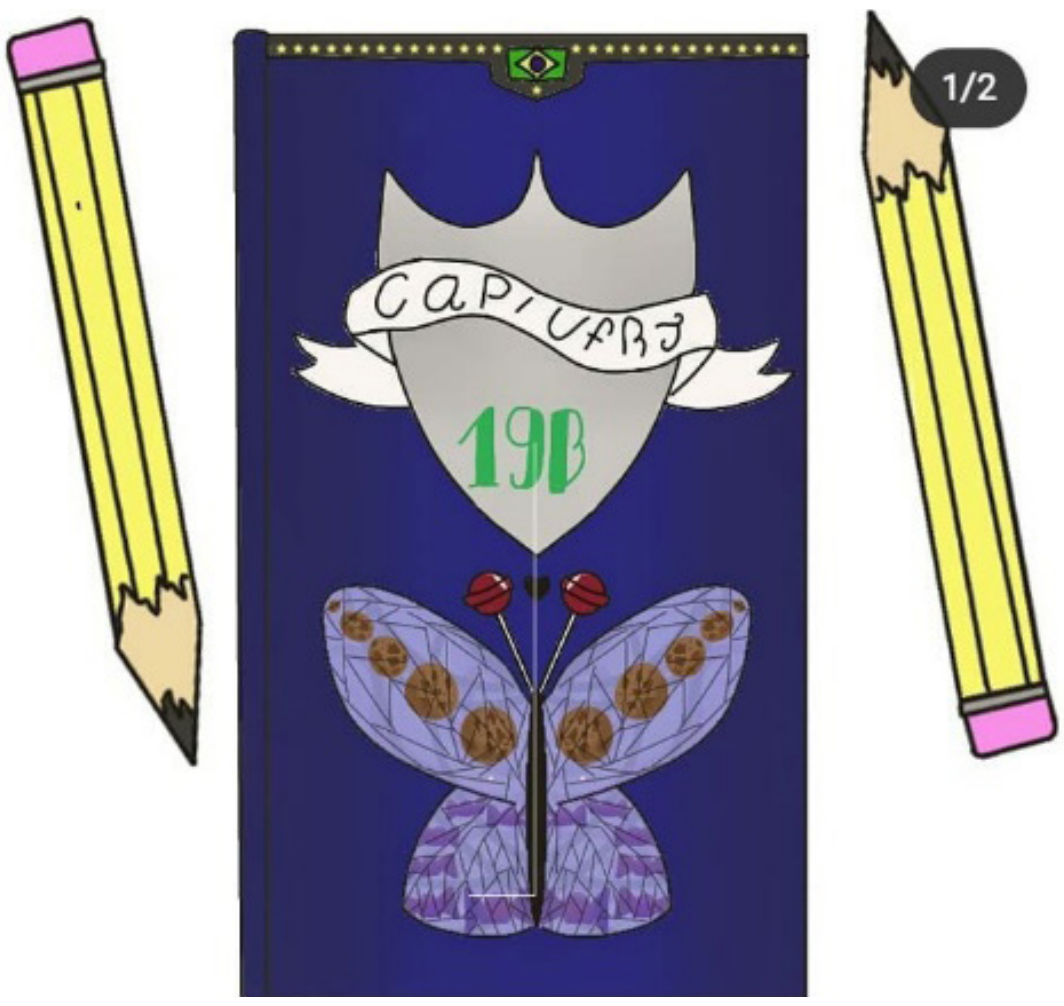

Fonte: Acervo das autoras ${ }^{6}$.

Figura 6 - Etapa de evolução: composição gráfica finalizada

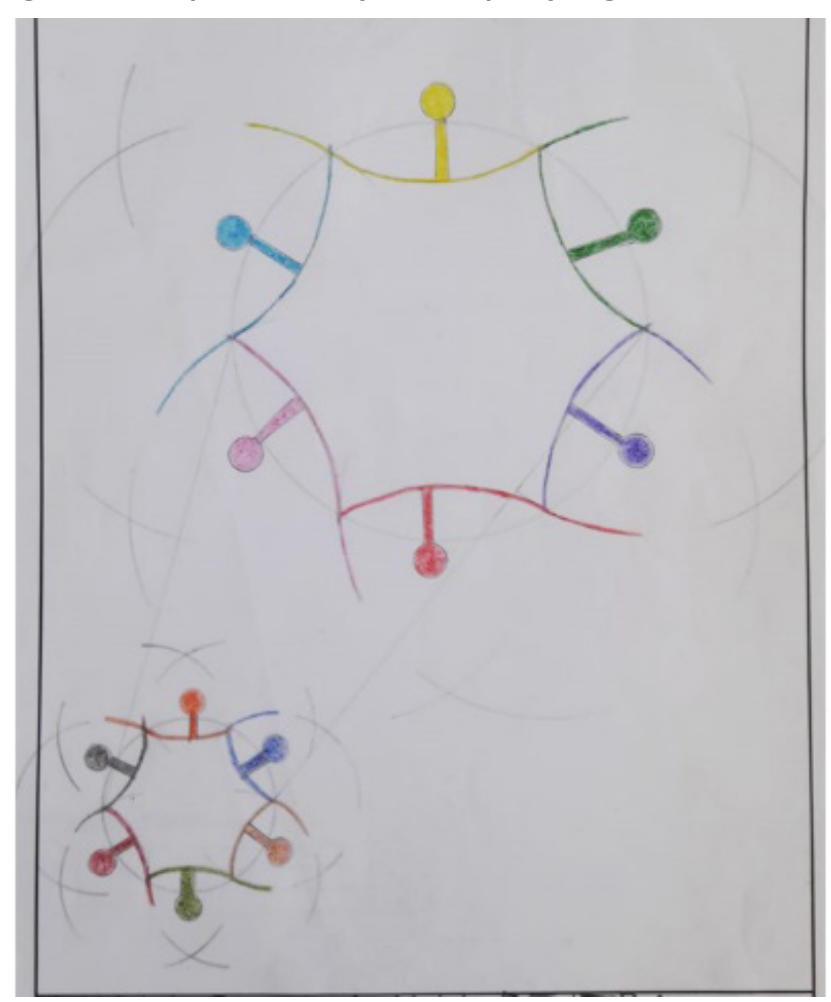

Fonte: Acervo das autoras?

6. Link de acesso ao vídeo: https://youtu.be/JrVmmVMgwvc.

7. Link de acesso ao vídeo: https://youtu.be/QL6JegU3KBY. 
Figura 7 - Etapa de evolução: composição gráfica finalizada

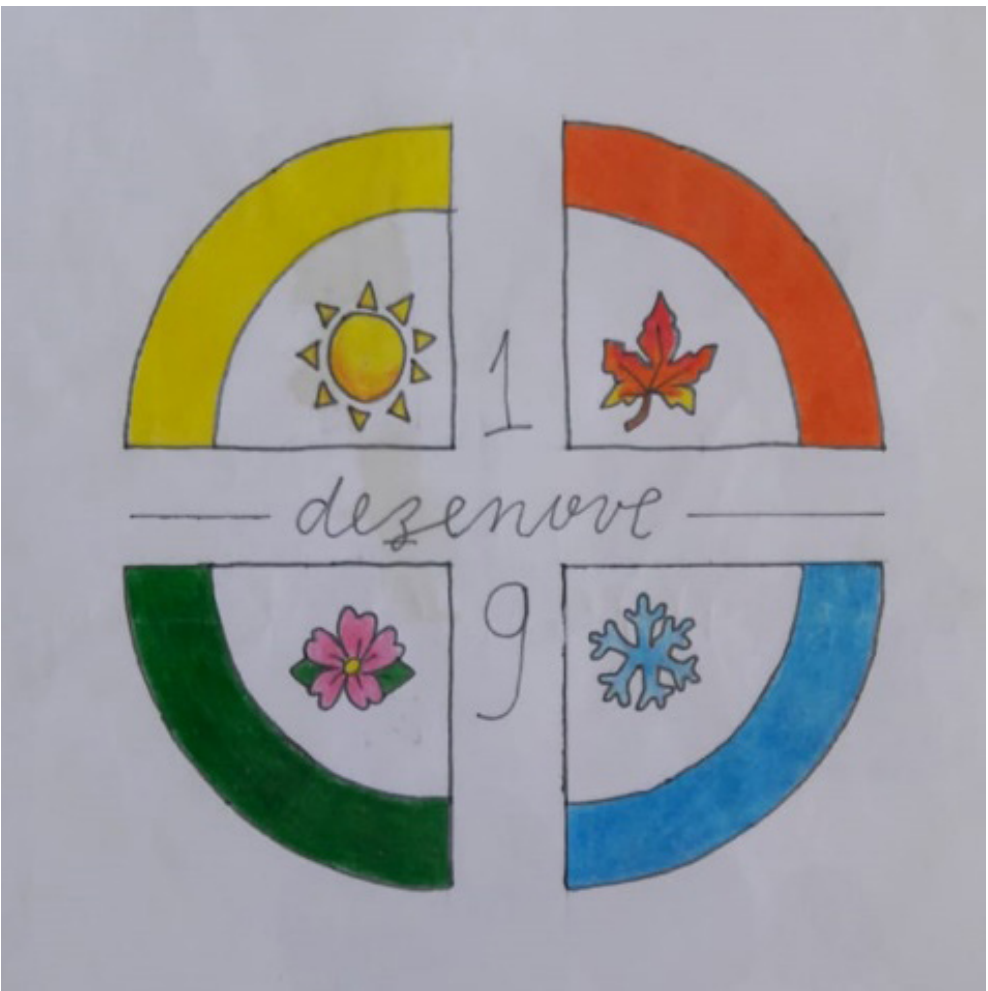

Fonte: Acervo das autoras ${ }^{8}$

Figura 8 - Etapa de evolução: composição gráfica finalizada

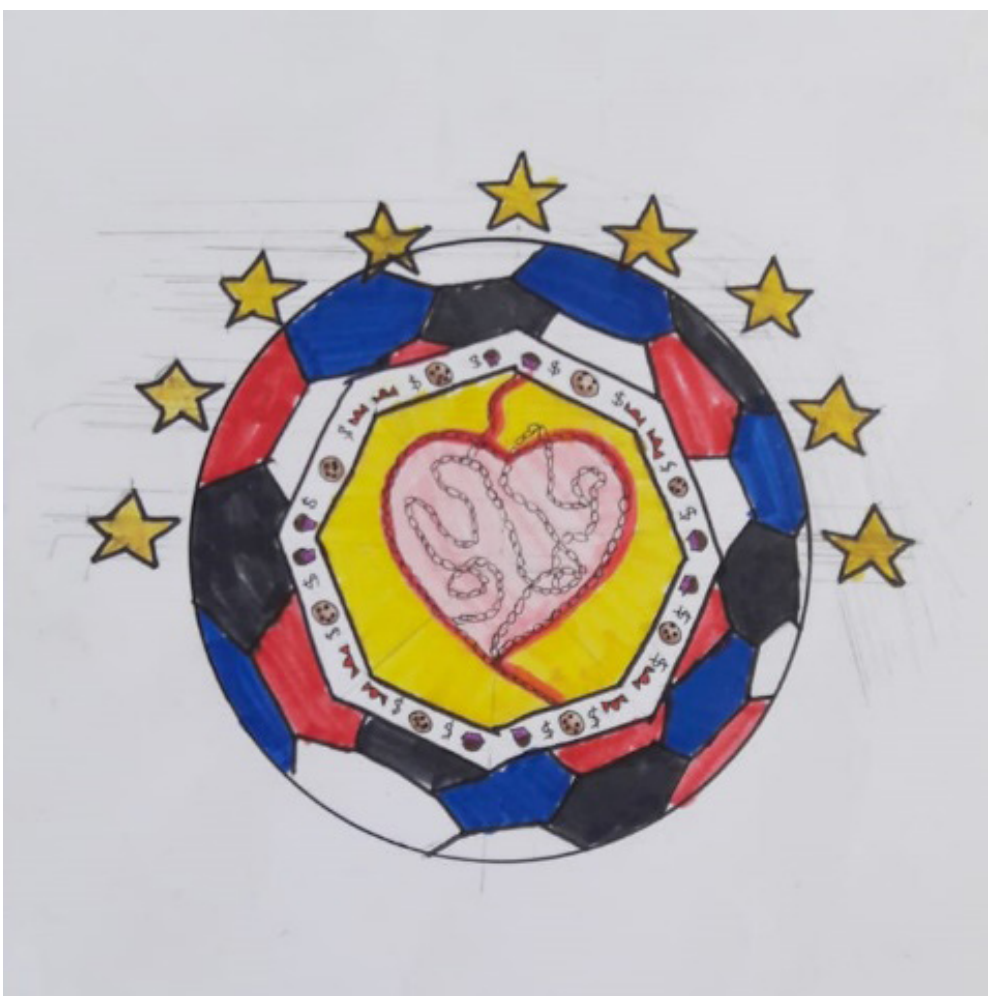

Fonte: Acervo das autoras 9 .

8. Link de acesso ao vídeo: https://youtu.be/HV4nvIRVRRA

9. Link de acesso ao vídeo: https://youtu.be/yQMZvtvN-nc. 
As Figuras 3 a 8 são referentes à etapa de evolução e ilustram os resultados dos processos de criação artística dentro dos parâmetros técnicos que foram propostos. Os links encaminham para vídeos, nos quais as ideias de elaboração de cada trabalho são explicadas pelos próprios criadores, os alunos.

Aspectos do Desenho Geométrico que foram trabalhados nessa proposta: construção de formas geométricas (as formas precisariam estar construídas corretamente, tendo utilizado os materiais de desenho e técnicas de representação adequada), organização espacial (o equilíbrio na disposição dos elementos gráficos que compõem o trabalho), transformações pontuais (é o componente curricular trabalhado na atividade que envolve técnicas de translação, reflexão, rotação e homotetia), simbologia das formas e cores (pesquisa que os alunos deveriam fazer para justificar a escolha de cores que comporiam o trabalho).

Outros aspectos trabalhados: trabalho em equipe, pesquisa, empatia, múltiplos conhecimentos, gerenciamento de tempo.

\section{Conclusão}

A complexa transformação do mundo nesta era digital exige que a escola se integre a essa nova configuração da globalização, que abrange aspectos políticos, econômicos, sociais, tecnológicos e ambientais. Por isso, a forma de ensinar precisa ser repensada para um ensino mais integrado e unilateral. Essa reformulação da educação precisa ser feita tanto para o ensino de formação de professores quanto para o ensino básico.

O Desenho Geométrico é uma disciplina que pode ser interessante e fazer sentido para os alunos, se trabalhada de uma forma que aguce a curiosidades e faça-os desenvolverem múltiplos saberes de forma autônoma.

Desse modo, é urgente que os professores de Desenho reconheçam que não é mais possível pautar as práticas pedagógicas em quadro, giz, régua e esquadro. O objetivo desse artigo não é sugerir práticas inovadoras, porém inalcançáveis, por conta das limitações de recursos, realidade de muitas escolas públicas. A proposta é que exista para além das reflexões sobre Desenho (raciocínio lógico e toda teoria em torno do assunto), mas também uma reflexão sobre o entorno e vivência de nossos alunos. Que esses elementos sejam ferramentas capazes de proporcionar, facilitar a aprendizagem e estimular a autonomia dos alunos. Em um mundo tão dinâmico o ensino não pode continuar com a sua rigidez.

A partir da análise do desenvolvimento e apresentação dessa atividade pelos alunos, constatamos que estes demonstraram muito mais interesse em relacionar o conhecimento do Desenho com o mundo através da aplicabilidade do Design, pois somos cercados por coisas que foram projetadas por designers e isso ressignifica a teoria do Desenho aguçando a curiosidade discente.

Dadas as circunstâncias descritas ao longo desse trabalho a respeito das práticas de ensino e aprendizagem do Desenho Geométrico nos dias atuais, conclui-se, então, que nessa nova era digital o futuro da disciplina é trabalhar com uma estreita relação com o Design, de forma multidisciplinar mergulhando em várias áreas do conhecimento através de analogias práticas que facilitam e auxiliam seu entendimento além de agregar valor à trajetória escolar do estudante.

\section{Referências}

BUENO, Marcelo. É possível promover uma Educação Gráfica nas escolas sem o ensino de Desenho? Revista Departamento de Desenho e Artes Visuais, Rio de Janeiro, v. 1, n. 1, p. 12-23, 2017. Disponível em: https://www.cp2.g12.br/ ojs/index.php/revistaddav/article/view/1162. Acesso em: 13 nov. 2019.

COSTA, Evandro Alexandre; ROSA, Milton. Fragmentos históricos do desenho geométrico no currículo matemático brasileiro. Juiz de Fora: Universidade Federal de Juiz de Fora, 2015.

CHRISTENSEN, Kaare; DOBLHAMMER, Gabriele; RAU, Roland. Ageing populations: the challenges ahead. The Lancet, United Kingdom, v. 374, n. 9696, p. 1119-1212, 3 out. 2009. Disponível em: https://www.thelancet.com/journals/ lancet/article/PIIS0140-6736(09)61460-4/fulltext. Acesso em: 14 ago. 2020.

DESCOLA. Relatório de Tendências: Descola. 2019/2020. Disponível em: https://descola.org/ebook/ebook-relatorio-tendencias. Acesso em: 24 abr. 2020. 
GAROFALO, Débora. Design Thinking: o que é e como usar em sala de aula. Nova Escola, São Paulo, 28 ago. 2018. Disponível em: https://novaescola.org.br/conteudo/12457/design-thinking-o-que-e-e-como-usar-em-sala-de-aula. Acesso em: 9 nov. 2019.

GEMIGNANI, Elizabeth Yu Me Yut. Formação de professores e metodologias ativas de ensino-aprendizagem: ensinar para a compreensão. Revista Fronteiras da Educação, Recife, v. 1, n. 2, 2012. Disponível em: https://www.uniavan.edu. br/uploads/arquivo/K2t3kZ.pdf. Acesso em: 18 jun. 2020.

MACHADO, Rosilene Beatriz. Entre vida e morte: cenas de um ensino de desenho. 2012. 254 f. Dissertação (Mestrado em Educação Científica e Tecnológica) - Programa de Pós-Graduação em Educação Científica e Tecnológica, Universidade Federal de Santa Catarina, Florianópolis, 2012.

PACHECO, José; SILVA, Andréa Vilella Mafra. Escola da Ponte: um espaço de múltiplas interações, cooperação e partilhas. Rio de Janeiro: Editora Rovelle, 2011. Disponível em: https://www.academia.edu/33576543/Escola_da_Ponte_ Vila_das_Aves_Portugal_Editora_Rovelle_.Acesso em: 15 jun. 2020.

UNIVERSIDADE FEDERAL DE PERNAMBUCO. Relatório Perfil Curricular. Recife: UFPE, 2017. Disponível em: https://www.ufpe.br/documents/39175/657360/Perfil_Curricular_LEG_106_2.pdf/aca73cd8-dd39-4307-baa1-ae4d26af5bbb. Acesso em: 26 fev. 2021.

UNIVERSIDADE FEDERAL DO PARANÁ. Grade curricular do curso de Expressão Gráfica. Recife: UFPE, 2012. Disponível em: http://www.exatas.ufpr.br/portal/cegraf/grade/. Acesso em: 18 jun. 2020.

ZUIN, Elenice de Souza Lodron. Da régua e do compasso: as construções geométricas como um saber escolar no Brasil. 2001. 211 f. Dissertação (Mestrado em Educação e Ensino de Ciências e Matemática) - Faculdade de Educação, Universidade Federal de Minas Gerais, Belo Horizonte, 2001.

Data de submissão: 19/06/2020

Data de aceite: $17 / 08 / 2020$ 